\title{
Simultaneous Analysis of Ibotenic Acid and Muscimol in Toxic Mushroom, Amanita muscaria, and Analytical Survey on Edible Mushrooms
}

\author{
(Food Hygienic Studies of Toxigenic Basidiomycotina. I) \\ (Received October 5, 1989)
}

\author{
Koujun TsunodA ${ }^{* 1}$, Noriko InouE*1, Yasuo Aoy AGI ${ }^{* 2}$ \\ and Tatsuyuki Sugahara**3 \\ (*1Suginami City Institute of Public Health Research, Tokyo: 3-20-3, Takaidohigashi, \\ Suginami-ku, Tokyo 168, Japan; ${ }^{* 2}$ Kagawa Nutrition Junior College, 3-24-3, \\ Komagome, Toshima-ku, Tokyo 170, Japan; ${ }^{3}$ Kagawa Nutrition College, \\ 3-9-21, Chiyoda, Sakado-City, Saitama 350-02, Japan)
}

\begin{abstract}
A convenient analytical method for ibotenic acid (IBO) and muscimol (MUS) in a toxic mushroom, Amanita muscaria (A. muscaria), was developed. IBO and MUS in the mushroom were extracted with $70 \%$ methanol. After filtration, IBO and MUS in the extract were determined by high performance liquid chromatography (HPLC) with a UV detector set at 210 $\mathrm{nm}$. The HPLC system adopted was ion-pair chromatography in the reverse-phase mode on an IRICA RP-18 $\left(\mathrm{C}_{18}\right)$ column $(4.0 \mathrm{~mm} \times 25 \mathrm{~cm})$ with sodium dodecyl sulfate as a counter ion. Recoveries of IBO and MUS added to the sample were more than $98 \%$, and the minimum detectable concentration of IBO or MUS was about $1 \mathrm{ppm}$. The concentrations of IBO and MUS in A. muscaria ranged from 258 to $471 \mathrm{ppm}$ and from 18 to $27 \mathrm{ppm}$, respectively. Neither of the compounds was detected in commercial edible mushrooms.
\end{abstract}

Key words: ibotenic acid; muscimol; toxic mushroom; Amanita muscaria; ion-pair liquid chromatography; spectroscopic analysis; NMR

\section{Introduction}

Uncultivated (wild) vegetables and mushrooms are extremely popular as foodstuffs in Japan. However, food poisoning by wild mushrooms including $A$. muscaria ${ }^{1)(3)}$ occurs every year $^{4)}$. A. muscaria contains $\alpha$-amino-3-hydroxy5-isoxazoleacetic acid, (ibotenic acid, IBO) and its decarboxylated derivative, 5-aminomethyl-3hydroxyisoxazole (muscimol, MUS), which are hallucinogenic ${ }^{5(7)}$. As a first step to prevent food poisoning caused by the mushroom, $A$. muscaria, it is necessary to develop a convenient analytical method for IBO and MUS. The analytical methods so far reported are time- consuming $^{8 / \sim 10}$, and IBO may decompose to MUS during the analysis. We have developed an analytical method for IBO and MUS and used it to evaluate the levels of IBO and MUS in $A$. muscaria and to follow the conversion of IBO to MUS during storage under various conditions.

\section{Experimental}

\section{Materials}

MUS was purchased from Sigma Chemical Co. Stock solutions of IBO and MUS (50 ppm) were prepared by dissolving IBO and MUS in 70\% methanol, and standard solutions for quantitative analysis were made by stepwise dilution of the stock solutions. All other materials, unless 
otherwise specified, were of reagent grade or the highest available grade from usual commercial sources.

\section{Samples}

1. The fruit bodies of $A$. muscaria were collected in Nagano Prefecture during summer 1987. The fresh fruit body was divided into two groups, which were kept in cool boxes, one (frozen sample) at $-20^{\circ} \mathrm{C}$ and the other (fresh sample) at $4^{\circ} \mathrm{C}$. A part of the frozen sample was freeze-dried (freeze-dried sample).

2. Commercial mushrooms (edible mushrooms) were purchased at supermarkets in Tokyo.

\section{Preparation of IBO}

Authentic IBO was prepared by extraction from the frozen sample. Purification and identification were conducted as follows; the sample $(15 \mathrm{~kg})$ was homogenized and extracted with about $70 \%$ methanol, and the solution was filtered through a filter paper No. 5A. The filtrate (about $45 \mathrm{~L}$ ) was concentrated to about onetwentieth of the initial volume with a flash evaporator, and subjected to chromatography on column-I (Amberlite IR-120, acidic form, $5 \mathrm{~cm}$ $\times 90 \mathrm{~cm}$, Rohm and Haas Co., U.S.A.) after defatting with ether $(5 \mathrm{~L} \times 2)$. IBO was eluted with 2 $N$ ammonia (10 L) after the column-I had been washed with water $(15 \mathrm{~L})$. The eluate was concentrated to dryness under reduced pressure at $45^{\circ} \mathrm{C}$, and the residue was dissolved in a small portion of water. The solution was placed on column-II (Dowex $1 \times 4$, acetate form, Dow Chemical Co., U.S.A.), and eluted with $2 N$ acetic acid $(\mathrm{AcOH}, 5 \mathrm{~L})$. The eluated was concentrated, the residue was dissolved in water, and the solution was adjusted to $\mathrm{pH} 2.2$ with hydrochloric acid. The solution was placed on column-III (Dowex $50 \mathrm{w} \times 4$, pyridine form, $5 \mathrm{~cm} \times 40 \mathrm{~cm}$ ), which was fractionated by linear gradient elution between pyridine-AcOH buffers $0.2 \mathrm{M}(\mathrm{pH}$ $3.1,2 \mathrm{~L})$ and $2.0 \mathrm{M}(\mathrm{pH} 5.0,2 \mathrm{~L})$. The eluate fractions which were ninhydrin-positive were concentrated, and the residue was dissolved in water. The solution was placed on column-II again, and elution was done with a linear gradient prepared from $\mathrm{AcOH}$ solutions of $0.1 \mathrm{~N}$ (1.5 L) and $2.0 N(1.5 \mathrm{~L})$. The eluate containing IBO was concentrated, and the residue was dissolved in water. The solution was applied to columnIII again, and eluted with $0.2 \mathrm{M}$ pyridine- $\mathrm{AcOH}$ buffer ( $\mathrm{pH} 3.1,2 \mathrm{~L}$ ). The eluate containing IBO was concentrated, and the residue was dissolved in water. The solution was applied to column-II, and eluted with $1 N \mathrm{AcOH}(5 \mathrm{~L})$. The eluate containing IBO was concentrated to a small volume. IBO was crystallized by adding ethanol to the solution, purified by recrystallization from aqueous ethanol, and dried in vacuo at $45^{\circ} \mathrm{C}$. Its purity was confired by thin layer chromatography, spectrophotometry and high performance liquid chromatography.

\section{Thin layer chromatography (TLC)}

Analytical TLC was conducted on silica gel plates (Kieselgel $60 \mathrm{~F} 254$, Merck) with the following solvent systems: $1, n$-propanol-10\% ammonium water $(95: 5, \mathrm{v} / \mathrm{v}) ; 2, n$-butanol-AcOHwater $(60: 20: 20, \mathrm{v} / \mathrm{v})$. After the development, spots were detected by spraying ninhydrin solu-

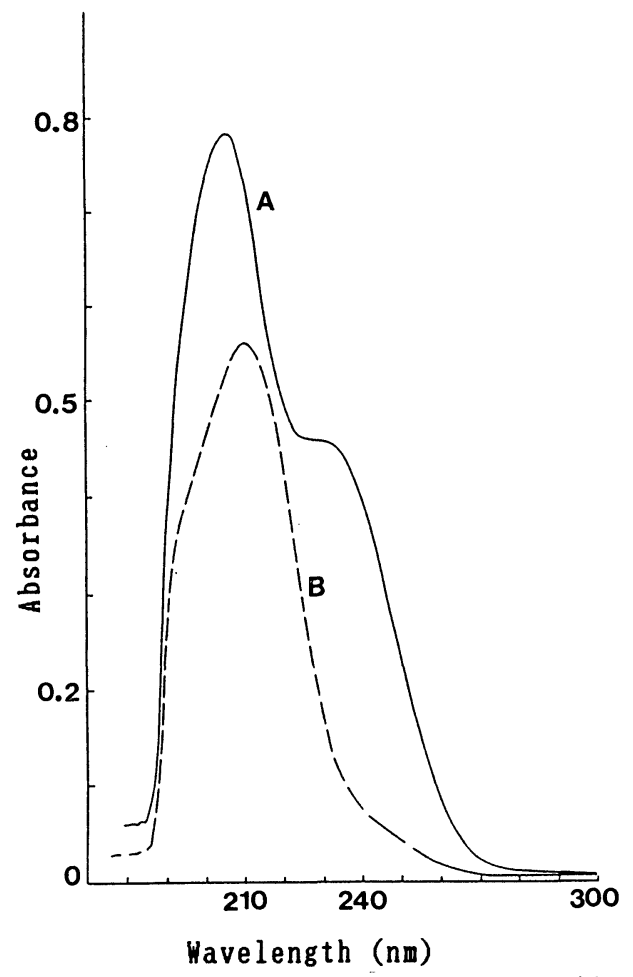

Fig. 1. Absorption spectra of ibotenic acid and muscimol in $25 \%$ methanol

A: muscimol $(50 \mathrm{ppm}) ; \quad$ B: ibotenic acid (50 ppm) 


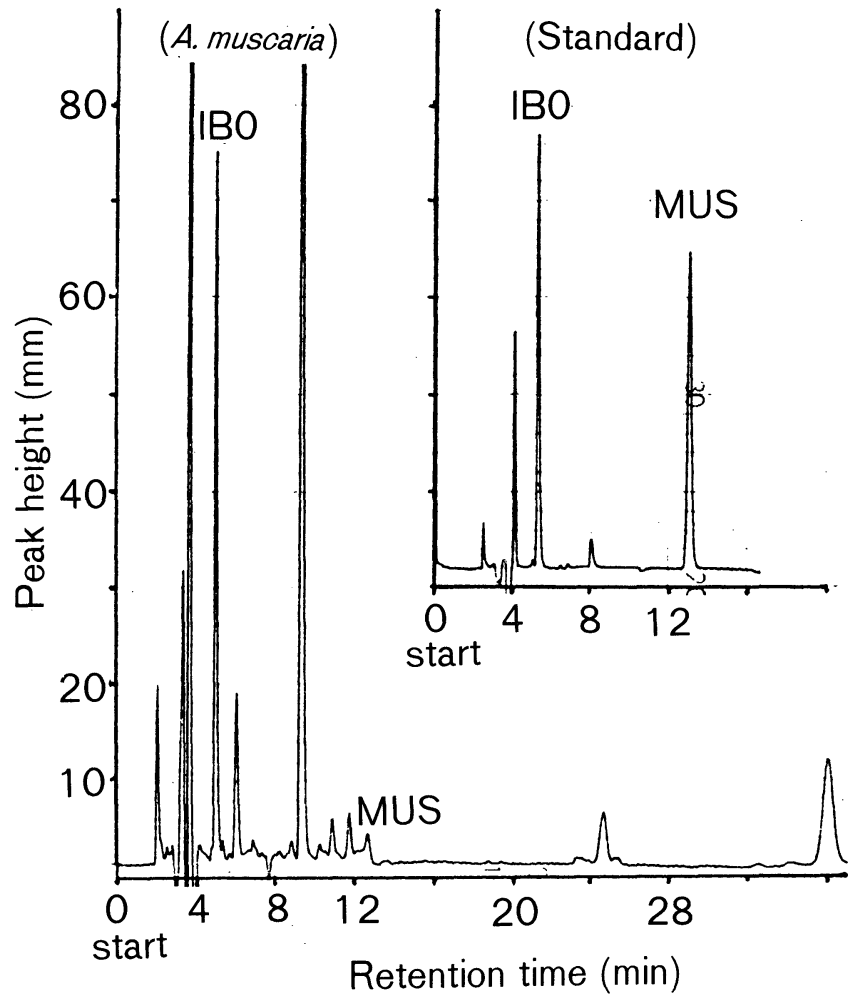

Fig. 2. Chromatograms of ibotenic acid and muscimol in A. muscaria extracts, and authentic standards (12.5 ng)

IBO: ibotenic acid; MUS: muscimol

Table 1. Recoveries of Ibotenic Acid and Muscimol Added to A. Muscaria

\begin{tabular}{|c|c|c|c|c|c|c|c|c|c|}
\hline & \multirow{2}{*}{$\begin{array}{l}\text { Added } \\
(\mu \mathrm{g} / \mathrm{g})\end{array}$} & \multicolumn{5}{|c|}{ Found $(\mu \mathrm{g} / \mathrm{g})$} & \multirow{2}{*}{$\begin{array}{l}\text { Mean } \\
(\mu \mathrm{g} / \mathrm{g})\end{array}$} & \multirow{2}{*}{$\begin{array}{c}\text { Recovery } \\
\text { (\%) }\end{array}$} & \multirow{2}{*}{ M. D. } \\
\hline & & No. 1 & 2 & 3 & 4 & 5 & & & \\
\hline \multirow[t]{2}{*}{ Ibotenic acid } & 0 & 187.2 & 185.1 & 187.6 & 186.4 & 184.9 & 186.2 & & \\
\hline & 40 & 226.7 & 224.9 & 226.8 & 225.5 & 225.0 & 225.7 & 98.7 & 0.8 \\
\hline \multirow[t]{2}{*}{ Muscimol } & 0 & 10.7 & 10.7 & 11.0 & 10.8 & 10.7 & 10.7 & & \\
\hline & 40 & 50.4 & 49.6 & 50.1 & 50.3 & 50.4 & 50.1 & 98.5 & 0.7 \\
\hline
\end{tabular}

M. D.: Mean deviation

Table 2. Changes of Concentration of IBO and MUS during Storage

\begin{tabular}{|c|c|c|c|c|c|c|c|c|c|c|c|}
\hline \multicolumn{2}{|l|}{ Periods } & \multicolumn{2}{|c|}{$\begin{array}{l}\text { First day } \\
\text { (ppm M. D.) }\end{array}$} & \multicolumn{2}{|c|}{$\begin{array}{l}\text { Second week } \\
\text { (ppm M. D.) }\end{array}$} & \multicolumn{2}{|c|}{$\begin{array}{l}\text { First month } \\
\text { (ppm M. D.) }\end{array}$} & \multicolumn{2}{|c|}{$\begin{array}{l}\text { Second month } \\
\text { (ppm M. D.) }\end{array}$} & \multicolumn{2}{|c|}{$\begin{array}{l}\text { Third month } \\
\text { (ppm M. D.) }\end{array}$} \\
\hline Exper & IBO & 379 & 9.3 & 382 & 7 & 388 & 11 & 376 & 17 & 38.2 & 1.1 \\
\hline at -20 & MUS & 21 & 1 & 20 & 3 & 2 & 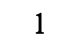 & U & 1 & 2 & 0.1 \\
\hline Experiment-2 & IBO & 418 & 2 & 414 & 3 & 409 & 7 & 406 & 8 & 41.5 & 0.5 \\
\hline at cool and dark & MUS & 22 & 1 & 21 & 1 & 22 & 2 & 23 & 1 & 2.0 & 0.1 \\
\hline Experiment-3 & IBO & 326 & 0 & 324 & 2 & 327 & 9 & 310 & 9 & 29.9 & 1.3 \\
\hline at $4^{\circ} \mathrm{C}$ in $\mathrm{MeOH}$ & MUS & 17 & 0 & 18 & 1 & 16 & 1 & 18 & 1 & 3.0 & 0.1 \\
\hline
\end{tabular}

Values represent the data from three samples.

M. D.: Mean deviation; IBO: ibotenic acid; MUS: muscimol 
tion.

High performance liquid chromatography (HPLC)

Analytical HPLC was performed with the isocratic solvent system described below, using an IRICA RP-18T $\left(\mathrm{C}_{18}\right)(4.0 \mathrm{~mm}$ i. d. $\times 250 \mathrm{~mm})$ column at a flow rate of $0.6 \mathrm{ml} / \mathrm{min}$ at $45^{\circ} \mathrm{C}$. The solvent system used for isocratic elution consisted of degassed water-acetonitrile-methanol mixture $(65: 20: 15)$ containing sodium dodecyl sulfate (SDS, $2.1 \mathrm{mM}$ ) and phosphoric acid (4 $\mathrm{m} M)(\mathrm{pH} 2.2)$.

Since the absorption maxima of IBO and MUS in $25 \%$ methanol are $211 \mathrm{~nm}$ and $207 \mathrm{~nm}$, respectively (Fig. 1), the HPLC eluates were monitored with a Tosoh Co. CCPE UV8010 UV detector set at $210 \mathrm{~nm}$. Analytical spectrophotometry $(350 \sim 195 \mathrm{~nm})$ of IBO and MUS was conducted with the same system.

\section{Extraction and analysis}

The freeze-dried sample $(2.5 \mathrm{~g})$ was homogenized (Nippon Seiki Co AM-7 homogenizer) in $70 \mathrm{ml}$ of $75 \%$ methanol, which was made up to $100 \mathrm{ml}$ with $75 \%$ methanol after being filtered through a filter paper (Toyo Roshi No. 5A). This solution was further filtered through a membrane filter (Toyo Roshi DISMIC-25, $0.45 \mu \mathrm{m}$ ), and a $5 \mu \mathrm{l}$ aliquot was subjected to analysis by HPLC. In the case of the fresh sample, $25 \mathrm{~g}$ was homogenized in $50 \mathrm{ml}$ of methanol, and the homogenate was filtered and made up to $100 \mathrm{ml}$ with methanol. Subsequent procedures were the same as described above.

\section{Recovery experiments}

The following recovery experiments were performed five times. The frozen sample $(100 \mathrm{~g})$ was homogenized, and the concentrations of IBO and MUS in the homogenate were determined by this method. Then $400 \mu \mathrm{g}$ each of IBO and MUS were blended in the homogenate (10 $\mathrm{g}$ ), and the concentrations were again determined. The recoveries of added IBO and MUS were calculated by subtraction of the known concentration in the frozen sample.

\section{Storage experiments}

The following three experiments were performed to examine the changes of concentration
Table 3. Contents of Ibotenic Acid and Muscimol in A. muscaria and Commercial Edible Mushrooms

\begin{tabular}{ccc}
\hline Sample & $\begin{array}{c}\text { IBO } \\
(\mathrm{ppm})\end{array}$ & $\begin{array}{c}\text { MUS } \\
(\mathrm{ppm})\end{array}$ \\
\hline
\end{tabular}

Amanita muscaria

1) Benitengutake

2) " 339

3) " 417

4) " 338

5) " 18258

Lentinus edodes

1) Shiitake ND ND

Tricholoma matsutake

1) Matsutake ND ND

Pleurotus ostreatus

$\begin{array}{lll}\text { 1) Hiratake } & \text { ND } & \text { ND } \\ \text { 2) " } & \text { ND } & \text { ND } \\ 3) \quad & \text { ND } & \text { ND }\end{array}$

Lyophyllum ulmarium

1) Bunashimeji ND ND

Grifola frondosa

1) Maitake

ND ND

Kuehneromyces nameko

$\begin{array}{lll}\text { 1) Nameko } & \text { ND } & \text { ND } \\ \text { 2) } " & \text { ND } & \text { ND }\end{array}$

Flammulina velutipes

$\begin{array}{lll}\text { 1) Enokitake } & \text { ND } & \text { ND } \\ \text { 2) } " & \text { ND } & \text { ND }\end{array}$

Agaricus bisporus

1) Mushroom ND ND

2) " ND ND

Auricularia auricula-Judal
1) Kikurage

IBO: ibotenic acid; MUS: muscimol; ND: not detected

Other names of the mushrooms

Pleurotus ostreatus : 1) Shimeji,

2) Shiroshimeji,

3) Oo-shimeji

Lyophyllum ulmarium : 1) Hon-shimeji

Kuehneromyces nameko: 2) Yama-nameko

Flammulina velutipes : 2) Tora-enokitake

Agaricus bisporus : : 2) Brown mushroom

of IBO and MUC in the mushroom during storage.

1. The sample was divided into three groups for a triplicate experiment (each group has six portions of $10 \mathrm{~g}$ apiece). Fresh samples $(10 \mathrm{~g})$ were kept at $-20^{\circ} \mathrm{C}$ after being chopped into small pieces.

2. Fresh samples $(10 \mathrm{~g})$ were kept in metha- 


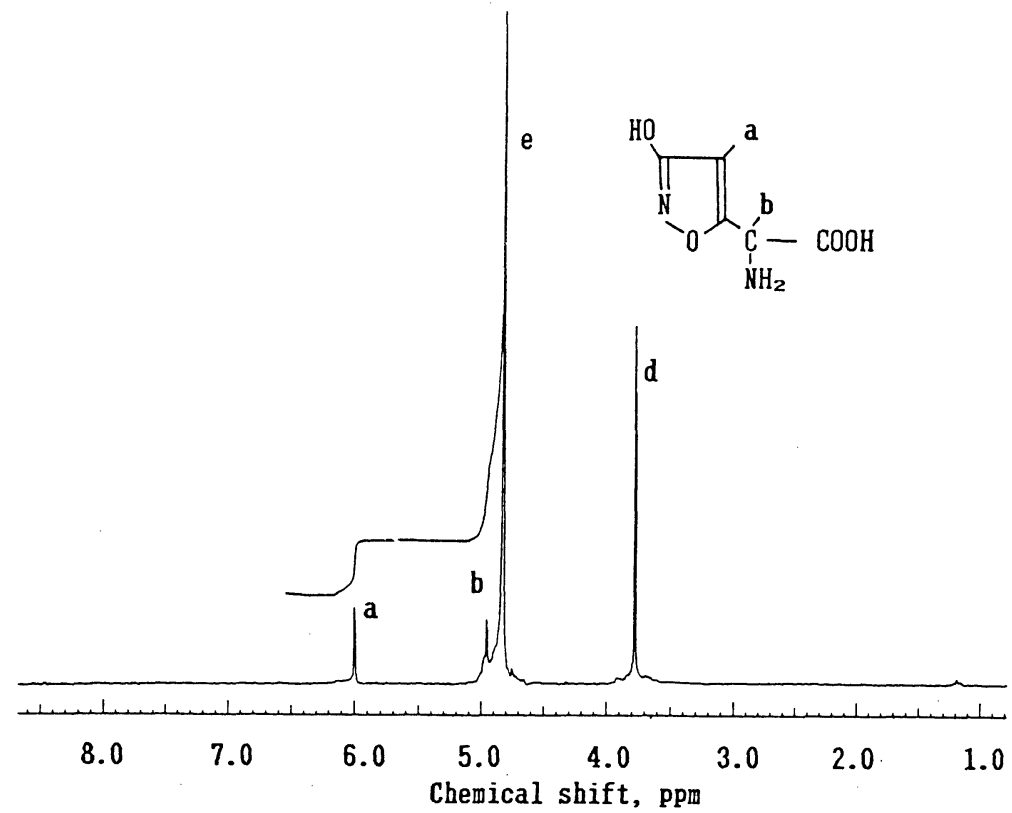

Fig. 3. ${ }^{1} \mathrm{H}$-NMR spectrum of $\alpha$-amino-3-hydroxy-5-isoxazoleacetic acid (ibotenic acid) in deuterium oxide

a, b: proton (H); d: dioxane (internal standard); e: $\mathrm{H}_{2} \mathrm{O}$ (moisture)

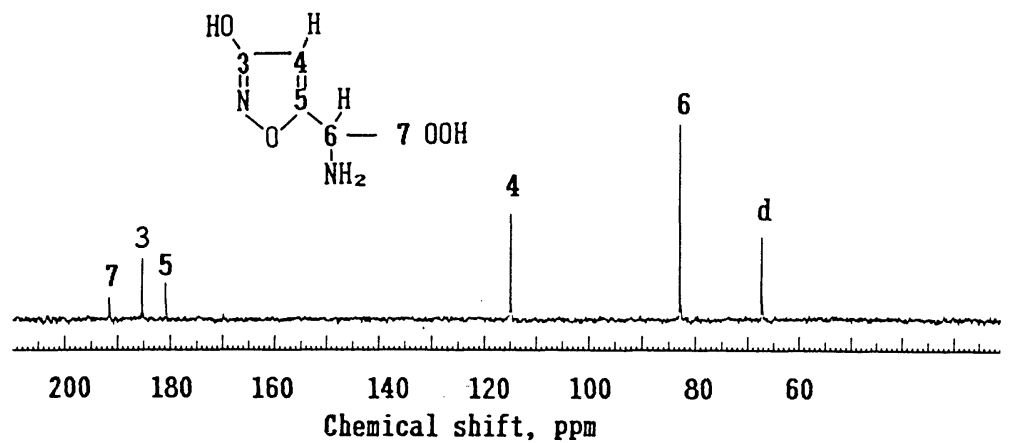

Fig. 4. ${ }^{13} \mathrm{C}$-NMR spectrum of $\alpha$-amino-3-hydroxy-5-isoxazoleacetic acid (ibotenic acid) in deuterium oxide

$3,4,5,6,7$ : carbon (C); d: dioxane (internal standard)

nol $(40 \mathrm{ml})$ at $4^{\circ} \mathrm{C}$ after homogenization.

3. Freeze-dried samples $(1 \mathrm{~g})$ were kept in a desiccator at room temperature in the dark after pulverization.

\section{Results and Discussion}

\section{Extraction}

Since IBO is said to be unstable under usual conditions, being decarboxylated to MUS, care is necessary during analysis. Decarboxylation of IBO is catalyzed by the enzyme decarboxylase to yield MUS. We selected $75 \%$ methanol as the solvent for extraction, since it deactivates decarboxylase in mushroom, and eliminates oily substances.

\section{2. $H P L C$}

In order to select a suitable column for good base-line separation by HPLC, we examined alumina, silica gel and so on. Among them, the $\mathrm{C}_{18}$ column seemed to be most suitable for our purpose, with the solvent system described above (Fig. 2).

\section{Recovery test}

The average recovery of IBO and MUS from 
A. muscaria spiked at the level of $40 \mathrm{ppm}$ was $98 \%$ with 0.8 and 0.7 mean deviation, respectively, the detection limit being $1 \mathrm{ppm}$.

\section{Changes of concentration of IBO and MUS during storing}

As shown in Table 1, decomposition of IBO to MUS did not occur during storage for 3 months under the conditions described above, suggesting enzymatic activity in mushroom is the main cause of the decomposition.

\section{IBO and MUS in mushroom obtained from su- permarkets}

We analyzed mushrooms purchased from super markets and detected no IBO or MUS (Table 2). In A. muscaria collected in Nagano prefecture, however, we detected IBO at levels of $258 \mathrm{ppm}$ to $471 \mathrm{ppm}$ and MUS at levels of 18 ppm to $27 \mathrm{ppm}$.

\section{Spectroscopic analysis ${ }^{11)}$}

IBO in A. muscaria was extracted with methanol, purified by ion exchange column chromatography and crystallized. Its identity was confirmed by TLC, HPLC (UV detection) and ${ }^{1} \mathrm{H}$ NMR and ${ }^{13} \mathrm{C}$-NMR spectroscopy (JEOL FX270 spectrometer).

1) ${ }^{1} \mathrm{H}$-NMR: The ${ }^{1} \mathrm{H}$-NMR chemical shifts of two methine protons of 4-isoxazole in dioxane were $\delta 6.01 \mathrm{ppm}$ and $\delta 4.94 \mathrm{ppm}$ (Fig. 3), in agreement with reported values ${ }^{12)}$.

2) ${ }^{13} \mathrm{C}$-NMR: Five carbon signals attributable to $\mathrm{C}_{3}$-hydroxyl $(\delta 185 \mathrm{ppm}), \mathrm{C}_{4}$-methine $(\delta 115$ $\mathrm{ppm}), \mathrm{C}_{5}$-isoxazole $(\delta 181 \mathrm{ppm}), \mathrm{C}_{6}-\alpha$-carbon $(\delta$ $82.9 \mathrm{ppm})$ and $\mathrm{C}_{7}$-carboxyl $(\delta 192 \mathrm{ppm})$ were clearly detected (Fig. 4).

These data confirmed the molecular structure of IBO as $\alpha$-amino-methyl-3-hydroxyisoxazoleacetic acid (monohydrate) ${ }^{5}$.

\section{Conclusion}

A sensitive simultaneous determination of IBO and MUS in A. muscaria was developed, allowing analysis of IBO without decomposition $^{5), 8)}{ }^{10)}$. IBO and MUS in the samples were stable at below $4^{\circ} \mathrm{C}$ in methanol, at below $-20^{\circ} \mathrm{C}$ or at room temperature in a desiccator after freeze-drying.

Methanol extraction of IBO and MUS provided a suitable sample solution for HPLC, which was performed in the reversed-phase mode on an ODS-column packed with end-capped silica gel using SDS as a counter ion. Baseline resolution of IBO and MUS was achieved with high sensitivity. Recovery was about $98 \%$ with a mean deviation below 0.8 . The detection limit of IBO and MUS was about $1 \mathrm{ppm}$.

Fresh A. muscaria contained $258 \sim 471 \mathrm{ppm}$ of IBO and $18 \sim 27 \mathrm{ppm}$ of MUS. The concentration of MUS in the mushroom was lower than has been found by other investigators $\left.{ }^{8)}, 10\right)$. IBO and MUS were not detected in commercial edible mushrooms.

\section{References}

1) Eugster, C. H., Muller, G. F. R., Good, R.: Tetrahedron Lett. 23, 1,813 1,815 (1965).

2) Johnston, G. A. R., Curtis, D. R., Grout, W.C. de., Duggan, A. W.: Biochem. Pharmacol. 17, 2,488 2,489 (1968).

3) Yamaura, Y., Komiyama, S., Fukuhara, M., Takabatake, A., Hashimoto T.: J. Food Hyg. Soc. Japan 24, 459 464 (1983).

4) Government Editing of Food Sanitation Division, Environmental Health Bureau, Ministry of Health and Welfare, Japan: "Occurrence Archives of Food Poisoning in Whole Country" (1975 1984).

5) Takemoto, T., Yokobe, T., Nakajima, T.: Yakugaku Zasshi 84, 1,186 1,188 (1964).

6) Bowden, K., Drysdale, A. C.: Tetrahedron Lett. 12, 727 728 (1965).

7) Muller, G. F. R., Eugster, C. H.: Helv. Chim. Acta 48, 910 926 (1965).

8) Gore, M. G., Jordan, P. M.: J. Chromatogr. 243, 323 328 (1982).

9) Lund, U.: Arch. Pharm. Chem., Sci. Ed. 7, 115 118 (1979).

10) Komiyama, S., Yamaura, Y., Nakazawa, H., Fujita, M., Kabasawa, Y.: Bunseki Kagaku 34, $161 \sim 165$ (1985).

11) Araki, S., Masiko, Y., Yamamoto, O., transl.: "Spectrometric Identification of Organic Compounds" 4th Ed., p. 168 277 (1984), Tokyokagakudozin Publishing Company, Tokyo.

12) Nakamura, N.: Chem. Pharm. Bull. 19, 46 51 (1971). 